\title{
IR Detection System for Driver Head Departure
}

\author{
Jui-Cheng Yen*, Hun-Chen Chen, Jia-Da Wang \\ Department of Electronic Engineering, National United University \\ Miaoli, Taiwan
}

*Corresponding Author: jcyen@ nuu.edu.tw

\begin{abstract}
The paper proposes a robust IR detection system to monitor driver head departure. In the system, the IR LEDs are sited on the back cushion behind the driver's head, the IR receivers are placed above and in front of the driver's head to receive IR LED signals, and the detection algorithm is developed to analyze the signals. By analyzing the changes of the received IR LED signals, driver head departure can be detected correctly. Its features are as follows. (i) Abnormal departure of the driver's head can be detected correctly. (ii) The action of viewing rear-view mirrors is recognized to be normal. (iii) The system cost is cheap. (iv) The design is robust to harsh climate and road environment. (v) The system design is safe to the driver's eyes. (vi) Because the IR light is invisible, the system doesn't interfere with the vision of the driver. (vii) It isn't influenced by the sunglass the driver wears.
\end{abstract}

Keywords: IR detection system, driver head departure, IR LED, IR receiver, harsh climate, sunglasses.

\section{Introduction}

When a driver is drowsy or absent-minded, his perception ability to surrounding environmental, handling ability to the car, and decision ability to traffic situation all diminish. They all easily result in serious traffic accident. Hence, the development of safe driving system to detect whether a driver is drowsy is very important to prevent traffic accident. Actually different brands of car corporations and research centers devote themselves to develop this kind of system over the past decade ${ }^{(1-4)}$. For example, the monitoring system "City safety" is the standard equipment in VOLVO XC60.

Many approaches ${ }^{(5-20)}$ for safe driving have been proposed. They can be classified into the following four categories. 1) The first category ${ }^{(5-8)}$ is based on driver's physiological signals such as brain waves, electrocardiogram signal, and pulse rate. 2) The second category ${ }^{(5,9-12)}$ focuses on the state of driver's head or face such as head movement, blink rate, eye closure, eyelid movement, and pupillary variation. 3) The third category ${ }^{(5,13-16)}$ is based on vehicle's behavior such as vehicle lateral position, distance between the driver's vehicle and the front car, and movement direction. 4) Methods ${ }^{(5,17-19)}$ based on the combination of above categories are the fourth category.

In the first category, it is necessary to attach sensors to the driver to measure the physiological signal. The attachment will interfere with the driver and hence limit its practical application. On the contrary, to monitor the state of driver's head or face in the second category, it just needs noncontact CMOS sensors instead of contact ones. Welldeveloped image processing techniques make the category to be a promising approach. However, how to overcome the violent illumination change outside the vehicle or eyesheltered effect due to sunglasses in the CMOS sensor approach is a big challenge. Moreover, some techniques shine infrared rays on driver's eyes to produce bright effect on pupil of driver's eyes, acquire the frame with bright pupil of driver's eyes, and analyze area change of pupil of driver's eyes to judge whether the driver is drowsy or absent-minded. They can obtain good results. However, this kind of system has three major disadvantages. 1) Shining infrared rays on the driver's eyes continuously may be harmful to the driver's eyes. 2) If the driver wears glasses, the light reflection from glasses will produce bright area which will be confused with the bright pupil. 3) The bright pupil effect is obvious in the nighttime, but it is unobvious in the daytime. Hence, the development of monitoring system safe to driver's eyes, robust to violent illumination variation, and superior to being effected by sunglasses is an important topic of the second category in the safe driving system. 


\section{IR Detection System for Driver Head Departure}

\subsection{System architecture}

To monitor whether the movement of the driver's head is abnormal, the IR detection system (IRDS) for driver head departure is proposed. The schematic lateral view of IRDS is shown in Fig. 1(a) and the schematic front view of IR LED arrangement is shown in Fig. 1(b). In the system, the IR LEDs are sited on the back cushion behind the driver's head, the IR receivers are placed above and in front of the driver's head to receive IR LED signals, and the head departure detection algorithm is developed to analyze the signals. By analyzing the changes of the received IR LED signals, driver head departure can be detected correctly.

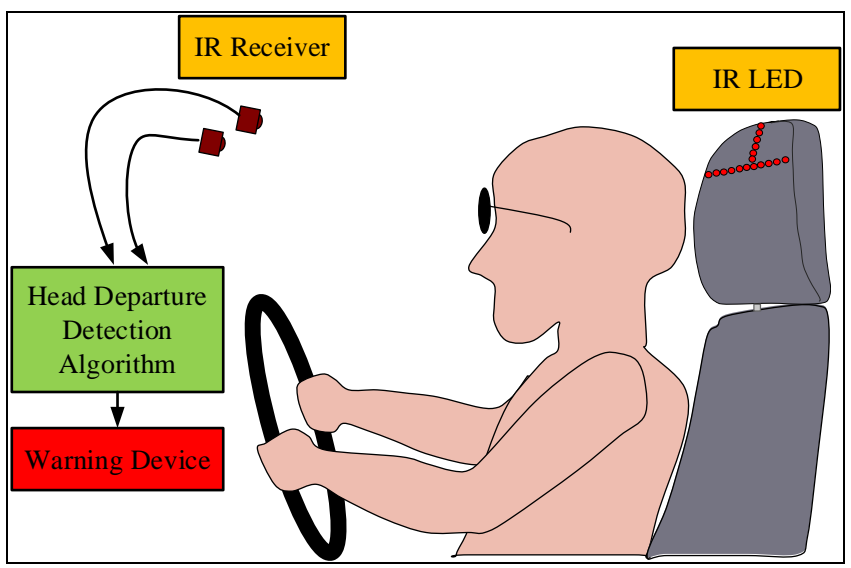

(a)

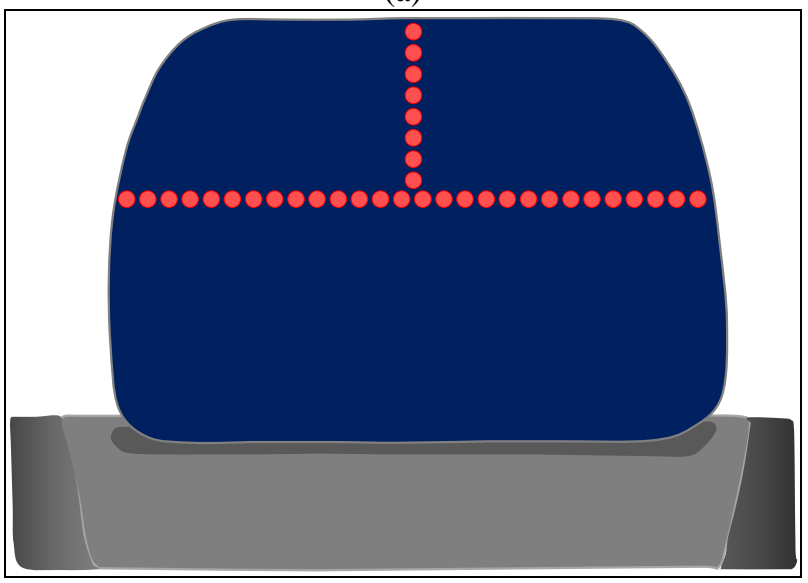

(b)

Fig. 1 (a) lateral view of IRDS (b) front view of IR LED arrangement.

\subsection{Head departure detection algorithm}

In IRDS, the head departure detection algorithm (HDDA) shown in Figure 2 is proposed to analyze the changes of the received IR LED signals. To describe HDDA, we adopt the notation $f_{i}(n), n=1,2, \ldots, N$, to denote the received IR signal from the $n$th IR LED in the $i$ th receiving scan. Moreover, use $f_{\text {stable }}(n), n=1,2, \ldots, N$, to denote the stable signal of the $n$th IR LED.

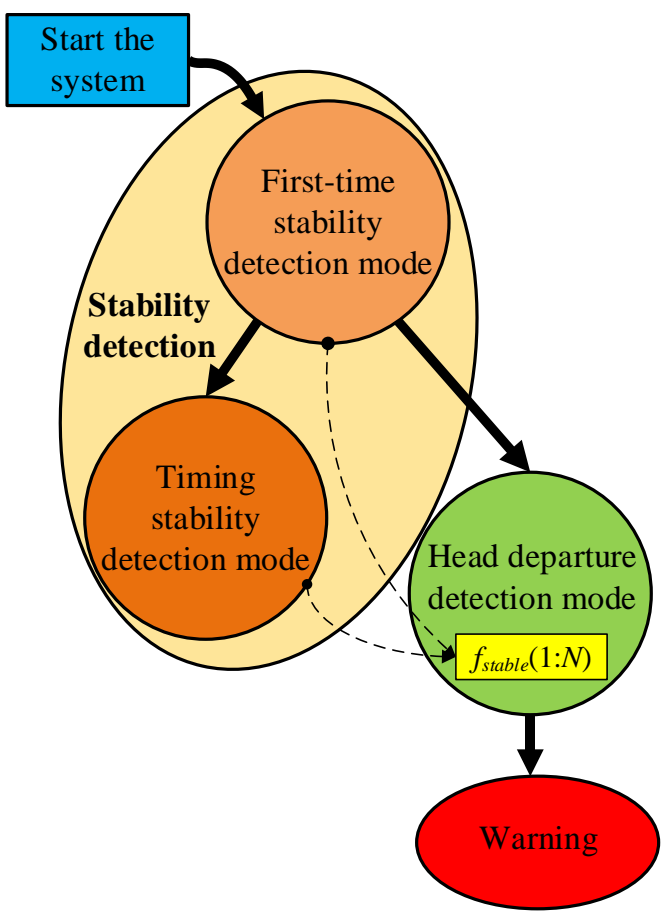

Fig. 2 The head departure detection algorithm in IRDS.

Based on the defined notations, HDDA is described as follows.

\section{First-time stability detection:}

If $f_{i-k}(n) \mathrm{s}, k=0,1, \ldots, 14$, are all the same for all the $N$ IR LEDs, then the first-time stability occurs and set $f_{\text {stable }}(n)$ to be $f_{i}(n), n=1,2, \ldots, N$.

\section{Timing stability detection:}

Since small variation of driver head position in the driving is normal, we detect whether the stability of driver head position occurs after the setted time is up. If it occurs, reset $f_{\text {stable }}(n)$ to be $f_{i}(n), n=1,2, \ldots, N$.

\section{Head departure detection:}

Considering the variations of the successive received IR LED signals in the vertical part, left part, right part, and all the parts, we can judge whether driver head departure is abnormal.

\section{Warning:}

The warning signal issued to the driver can be the sound from loudspeaker, figures in screen, music from player, light from source, vibration from vibrator, and so forth. 


\section{MATLAB Simulation Results}

To demonstrate the effectiveness of the proposed IRDS, the system is set up in our laboratory and shown in Figure 3. In the system, there are 36 IR LEDs in total, including 8 LEDs in the vertical part and 28 LEDs in the horizontal part. All the IR LEDs are controlled by the control unit MPC89E515A. Moreover, we use 2 IR receivers. The head departure detection algorithm is implemented in the Altera DE2-115 development platform with a Cyclone IV EP4CE115 FPGA.

After the system is set up, we verify the system in our laboratory. The verification result is recorded. Six represented frames are shown in Fig. 4. The video is uploaded to YouTube ${ }^{(21)}$ and can also be played in Fig. 4(f).

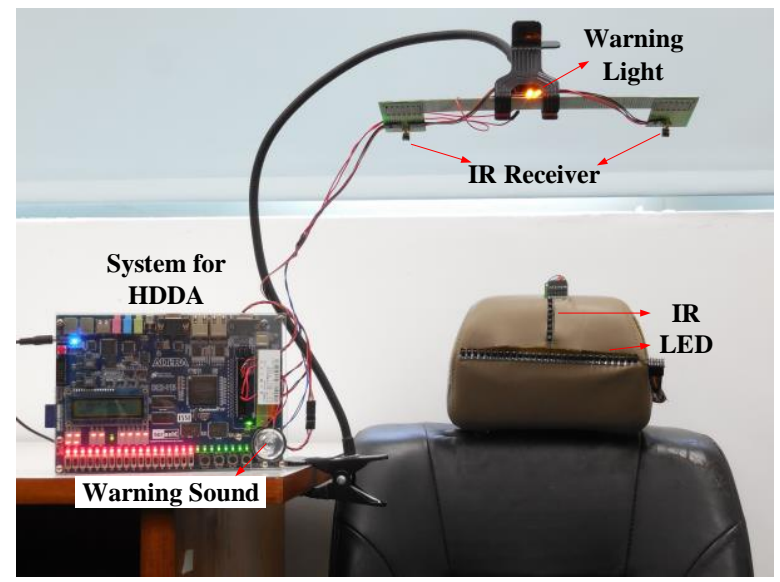

Fig. 3 The system set up in the laboratory.

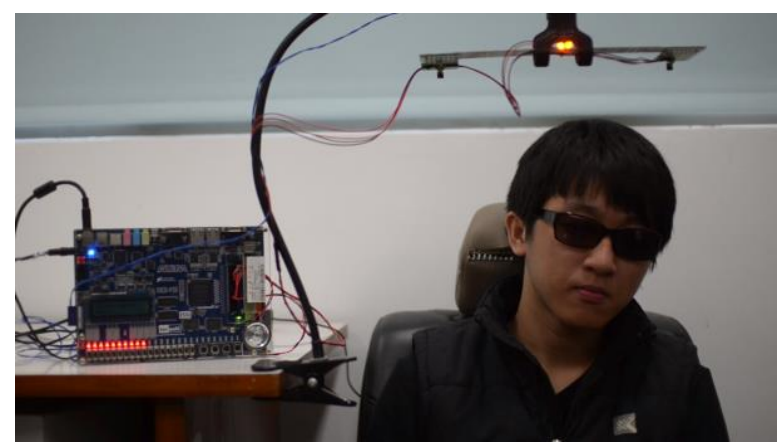

(a)

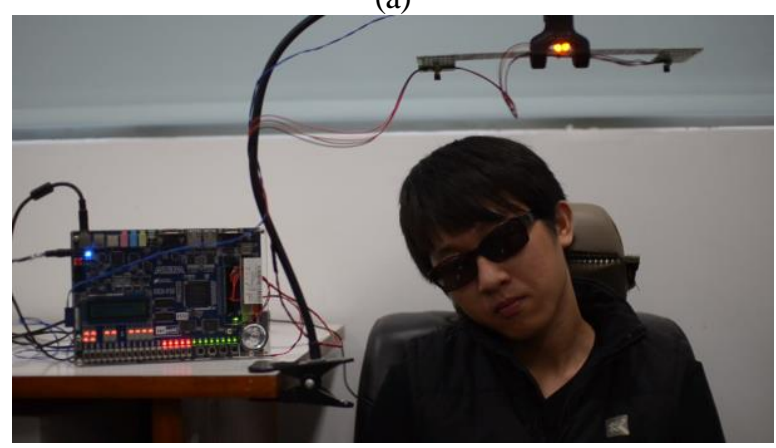

(b)

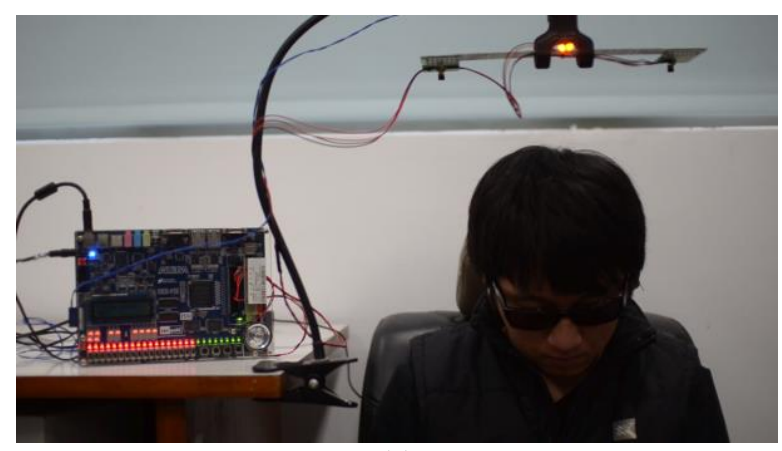

(c)

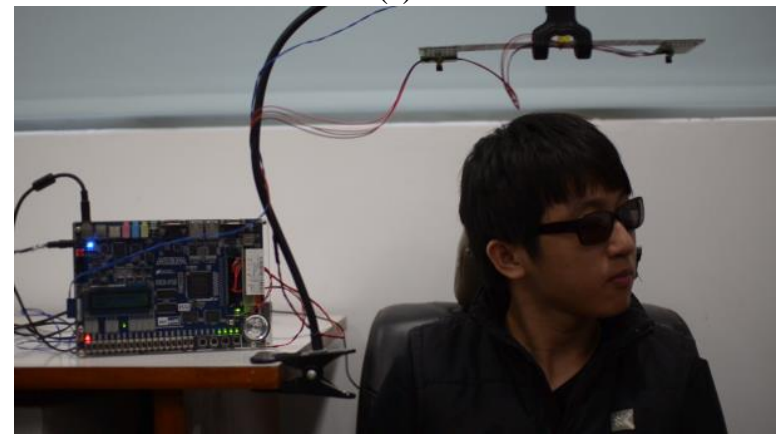

(d)

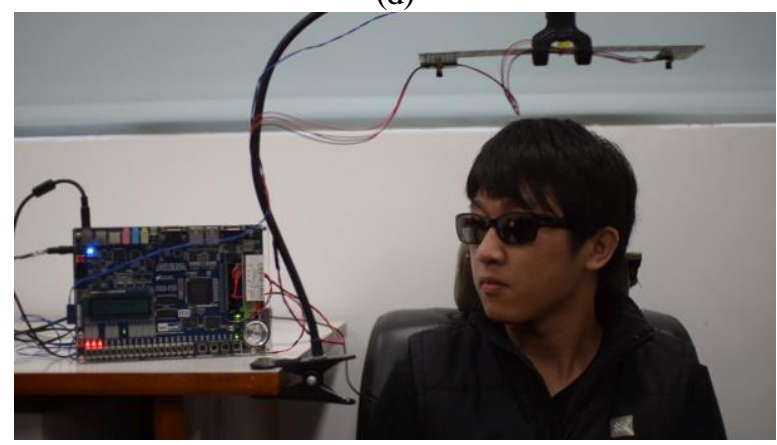

(e)

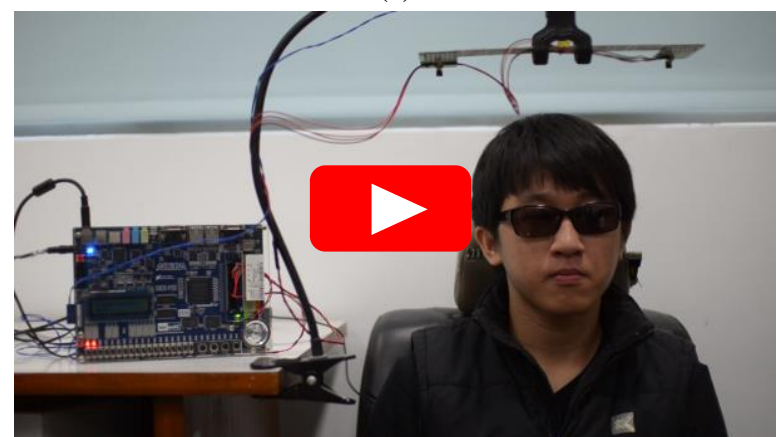

(f)

Fig. 4 (a) warning for departure to left, (b) warning for departure to right, (c) warning for departure to front, (d) normal for watching the left rear-view mirror, (e) normal for watching the right rear-view mirror, (f) the video of the verification results uploaded to YouTube.

Inspecting the video played in Fig. 4(f), all the nodding behaviors are detected exactly and the action the driver watches the rear-view mirror is judged to be normal. The video demonstrates the features of the proposed IRDS clearly. 


\section{Conclusions}

In the paper, the robust IR detection system for driver head departure has been proposed. It has the following features. (i) Abnormal departure of the driver's head can be detected correctly. (ii) The action of viewing rear-view mirrors is recognized to be normal. (iii) The system cost is cheap. (iv) The design is robust to harsh climate and road environment. (v) The system design is safe to the driver's eyes. (vi) Because the IR light is invisible, the system doesn't interfere with the vision of the driver. (vii) It isn't influenced by the sunglass the driver wears.

Finally, we believe that the active safe driving system can greatly benefit by adopting the proposed system.

\section{Acknowledgment}

This work was supported in part by the Ministry of Science and Technology, R.O.C. under Grant MOST 1032221-E-239 -035.

\section{References}

(1) http://news.u-car.com.tw/16781.html

(2) http://cool3c.incar.tw/article/56764

(3) http://www.ford.com

(4) http://www.artc.org.tw

(5) Y. Dong, Z. Hu, K. Uchimura, and N. Murayama, "Driver inattention monitoring system for intelligent vehicles: A Review," IEEE Trans. on Intelligent Transportation Systems, vol. 12, Iss. 2, pp. 596 - 614, June 2011.

(6) R. N. Khushaba, S. Kodagoda, S. Lal, and G. Dissanayake, "Driver drowsiness classification using fuzzy waveletpacket-based feature-extraction algorithm," IEEE Trans. on Biomedical Eng., vol. 58, Iss. 1, pp. 121-131, Jan. 2011.

(7) J. F. Coughlin, B. Reimer,B. Mehler, "Monitoring, managing, and motivating driver safety and well-being," IEEE Pervasive Computing, vol. 10, Iss. 3, pp. 14-21, 2011.

(8) A. Kircher, M. Uddman, and J. Sandin, "Vehicle control and drowsiness," Swedish National Road and Transport Research Institute, 2002.

(9) R. C. Coetzer, and G. P. Hancke, "Eye detection for a real-time vehicle driver fatigue monitoring system," 2011 IEEE Intelligent Vehicles Symp. (IV), pp. 66 - 71, 5-9 June 2011.

(10)D. F. Dinges, and R. Grace, "PERCLOS: A valid psychophysiological measure of alertness as assessed by psychomotor vigilance," US Department of Transportation, Federal highway Administration. Publication Number FHWA-MCRT-98-006.

(11) H. Singh, J. S. Bhatia, and J. Kaur, "Eye tracking based driver fatigue monitoring and warning system," 2010 India International Conference on Power Electronics (IICPE), pp. 1-6, 28-30 Jan. 2011.

(12) L. M. Bergasa, J. Nuevo, M. A. Sotelo, R. Barea, and M. E. Lopez, "Real-time system for monitoring driver vigilance," IEEE Trans. on Intelligent Transportation Systems, vol. 7, no. 1, March 2006.

(13) L. Li, Y. Chen and L. Xin, "Driver fatigue detection based on mouth information," 2010 8th World Congress on Intelligent Control and Auto. (WCICA), pp. 60586062, 7-9 July 2010.

(14) C. F. Wu; C. J. Lin; C. Y. Lee, “Applying a functional neurofuzzy network to real-time lane detection and frontvehicle distance measurement," IEEE Trans. on Systems, Man, and Cybernetics, Part C: Applications and Reviews, vol. 42, Iss. 4, pp. 577-589, 2012.

(15) T. Ersal, H. J. A. Fuller, O. Tsimhoni, J. L. Stein, and H. K. Fathy, "Model-based analysis and classification of driver distraction under secondary tasks," IEEE Trans. Intelligent Transportation Systems, vol. 11, no. 3, pp. 692-701, Sep. 2010.

(16) T. H. Chang, C. S. Hsu, C. Wang, L. K. Yang, "Onboard measurement and warning module for irregular vehicle behavior," IEEE Trans. on Intelligent Transportation Systems, vol. 9, Iss. 3, pp. 501-513, 2008.

(17) T. Wakita, K. Ozawa, C. Miyajima, K. Igarashi, K. Itou, K. Takeda, and F. Itakura, "Driver identification using driving behavior signals," IEICE Trans. Information System, vol. E89-D, no. 3, pp. 1188-1194, Mar. 2006.

(18)B. G. Lee and W. Y. Chung, "Driver alertness monitoring using fusion of facial features and biosignals," IEEE Sensors Journal, vol. 12, pp. 2416-2422, 2012.

(19) B. G. Lee, S. J. Jung, and W. Y. Chung, "Real-time physiological and vision monitoring of vehicle driver for non-intrusive drowsiness detection," IET Communications, vol. 5, Iss. 17, pp. 2461-2469, 2011.

(20) H. D. Rosario, J. S. Solaz, N. Rodriguez, and L.M. Bergasa, "Controlled inducement and measurement of drowsiness in a driving simulator," IET Intelligent Transport Systems, vol. 4, pp. 280-288, 2010.

(21) https://youtu.be/1g-fBFDfXsU 